\title{
Preparation of foamed commercially pure aluminum by air pressure infiltration process
}

\author{
Jianning $\mathrm{Wei}^{1,}$, , Genmei $\mathrm{Li}^{2}$, Cuiling $\mathrm{Hou}^{1}$, Gaoping $\mathrm{Xu}^{1}$, and Junqing $\mathrm{Wu}^{1}$ \\ ${ }^{1}$ Department of Science and Key Laboratory for Solid State Microstructure of Jiangxi Province, Jiujiang University, \\ Jiujiang, Jiangxi 332005, China \\ ${ }^{2}$ Department of Mechanical and Materials Engineering, Jiujiang University, Jiujiang, Jiangxi 332005, China
}

\begin{abstract}
This work reports the technology of preparation about foamed commercially pure aluminum, which was prepared by an air pressure infiltration process. The method consists of five sequential processes: particles preprocessing, shape body system for molding, preheating, infiltration casting, machining and cleaning. The porosity of foamed commercially pure aluminum is $68 \%$. The mean diameter of macroscopic pore is on the order of a millimeter $(1.0$ $\mathrm{mm}$ ) in the foamed commercially pure aluminum with open-pore structure.
\end{abstract}

Keywords: foamed commercially pure aluminum; air pressure infiltration process.

\section{Introduction}

In the last two decades cellular materials have been developed and are growing in use as new engineering materials [1,2]. These exceptionally lightweight materials possess unique combinations of properties, such as impact energy absorption capacity, air and water permeability, unusual acoustic properties, low thermal conductivity and good electrical insulating properties. Foamed metal materials preparation method is not only with the structural and performance is closely related, and a direct impact on the metal practical applications $[3,4]$. The paper detailed description an air pressure infiltration process of foamed commercially pure aluminum.

a Corresponding author : cl_weijianning@jju.edu.cn 


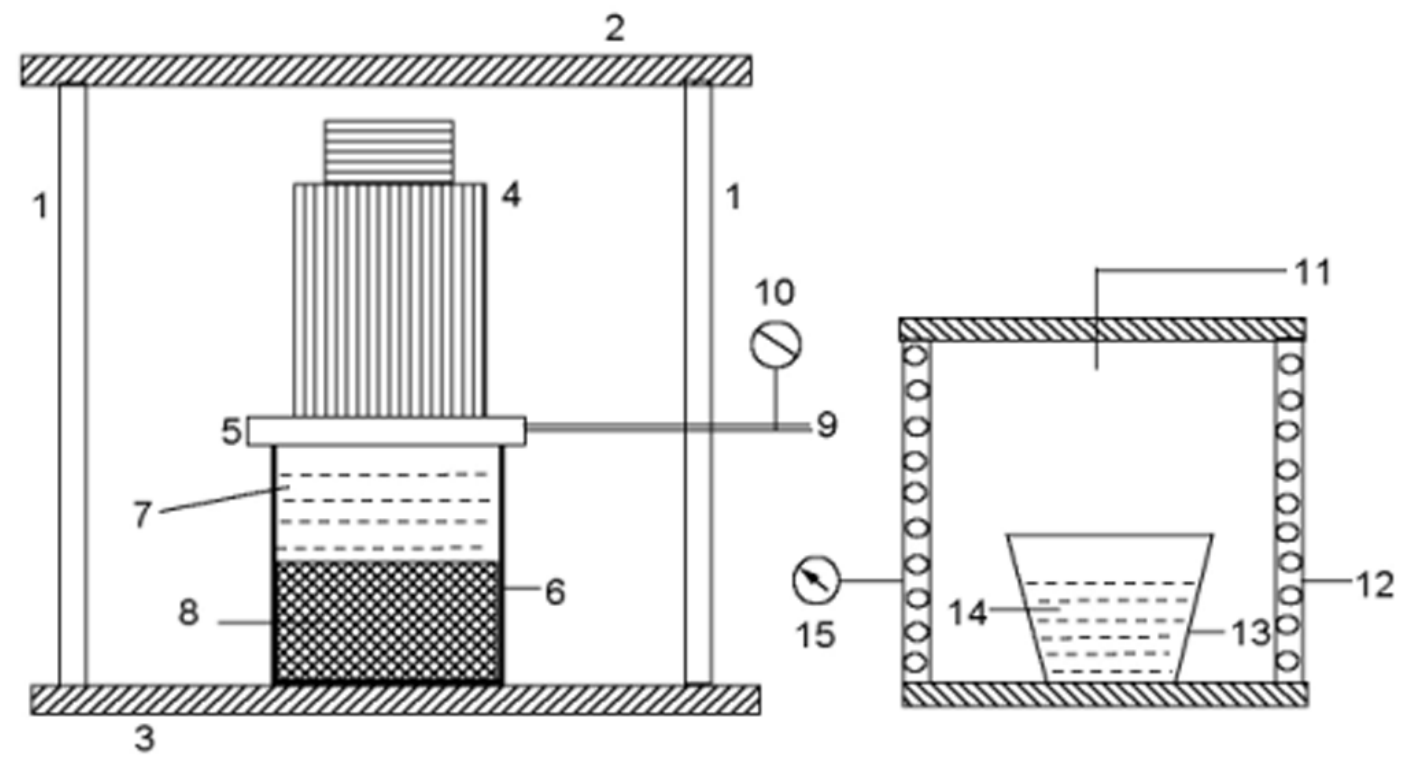

Figure 1. The device diagram of air pressure infiltration process

(1 pillar, 2 up sustained board, 3 down sustained board, 4 lifting jack, 5 metal mold lid, 6 metal mold with porous plate, 7 metal liquid, 8 particles prefabricated, 9 gas pipe, 10 barometer, 11 thermocouple, 12 well-type resistance furnace, 13 crucible, 14 smelting metal, 15 temperature controller)

\section{Device of air pressure infiltration process}

Figure 1 shows the device diagram of air pressure infiltration process [4]. Through this simple device, foamed commercially pure aluminum with porosity up to $68 \%$, homogeneous structures and open-pore were achieved.

\section{The preparation process of air pressure infiltration process}

\subsection{Particles preprocessing}

The commercially salt $(\mathrm{NaCl})$, a white crystalline, density 2.16 g. $\mathrm{cm}^{-3}$, melting point $804{ }^{\circ} \mathrm{C}$, boiling point $1413{ }^{\circ} \mathrm{C}$, are soluble in water [5]. The commercially salt particles are baked at lower temperatures about $180{ }^{\circ} \mathrm{C}$ for 10 hours, removal crystal water, avoid salt particles burst from the broken, so the gap between particles that the metal.

\subsection{Shape body system for molding}

The shape body are the salt particles, which were prefabricated the firm for $25 \%$. Using loose salt particles will affect the performance of liquid commercially pure aluminum. Compacted salt particles, can guarantee the connectivity of metal holes and prevent agglomeration of salt particles.

\subsection{Preheating}

In the well type resistance furnace, the preheating of the mould and the salt particles is a key process. Preheat the high temperature, the ability to penetrate to the metal, but will lower molds is life. Preheat the temperature is low, the metal solidified to block the frontier passes quickly, the distribution and 
reduce the forming ability. In this process, at about $470{ }^{\circ} \mathrm{C}$, macroscopic $\mathrm{NaCl}$ particulates $(1.0 \mathrm{~mm})$ were preheated as performs in a crucible.

\subsection{Infiltration casting}

In the commercially pure aluminum, the aluminum weight of the percentage is $99.5 \%$, density 2.70 g. $\mathrm{cm}^{-3}$, melting point about $660{ }^{\circ} \mathrm{C}$, commercially pure aluminum for its light, at the top of the lower and such a fine performance was regarded as creating composite best matrix materials $[4,6]$. The low damping matrix material commercially pure aluminum is a kind of plastic higher and the intensity of the lower materials. The commercially pure aluminum were refined in the well-type resistance furnace, about degree of superheat of $50{ }^{\circ} \mathrm{C}$, which made for metal liquid penetrated successful. And then poured into the prefabricated shape body system, pressure quickly, the pressure of time to make the metal under pressure and metal organization will be more dense, at the same time, the pressure to overcome the metal surface tension.

\subsection{Machining and cleaning}

When the casting is solidified, the casting cutted by electric sparking machine in a bar shape, so that to damping experiment. After infiltration process, sodium chloride particulates were leached out with water to leave pores in the foamed commercially pure aluminum specimens.

\section{Foamed commercially pure aluminum typical photo}

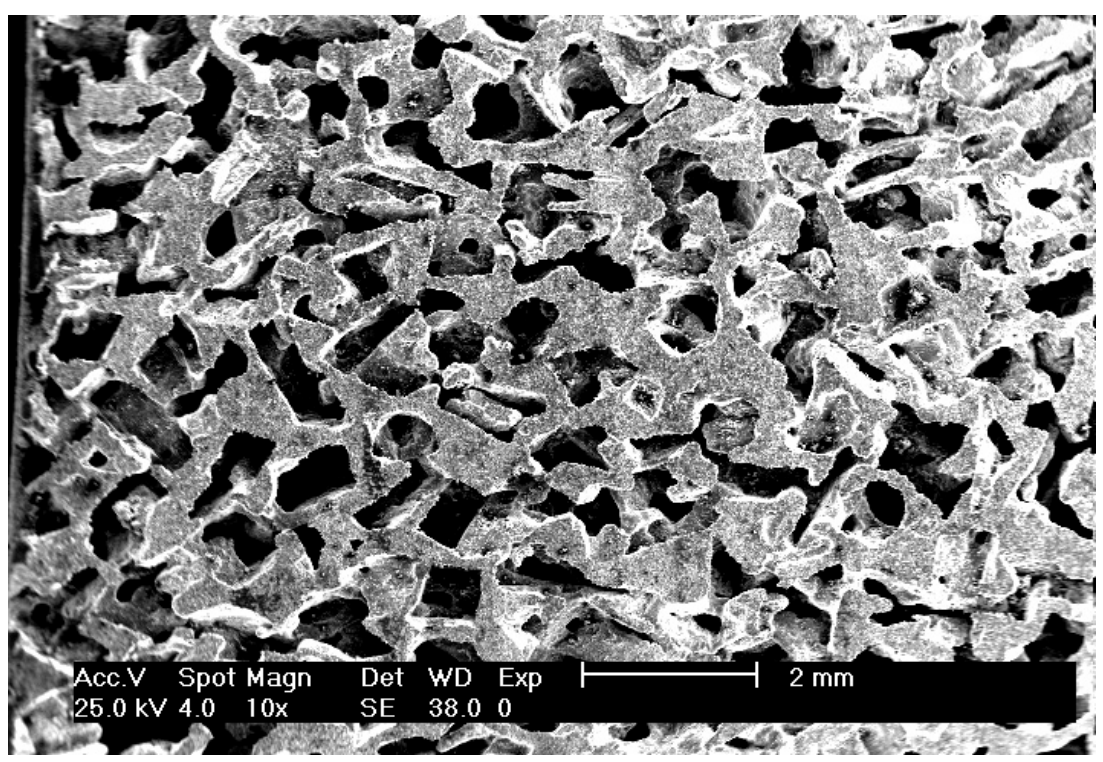

Figure 2. The typical photo of foamed commercially pure aluminum

Figure 2 shows the typical photo of foamed commercially pure aluminum prepared by air pressure infiltration process. The macroscopic pores in the foamed commercially pure aluminum are open and most are regular circle [4,7]. Foamed commercially pure aluminum has a quite uniform macroscopic pore and density distribution through the section. The specimens' density is determined from its weight and physical dimensions. From this density, the macroscopic pore porosity $(p)$ is given by 
$p=1-\frac{\rho}{\rho_{s}}$, where $\rho$ is the density of the foamed commercially pure aluminum and $\rho_{s}$ the density of the bulk commercially pure aluminum.

\section{Conclusions}

Foamed commercially pure aluminum were prepared successfully by an air pressure infiltration process, which had five sequential processes: particles preprocessing, shape body system for molding, preheating, infiltration casting, machining and cleaning. The air pressure infiltration process can be accurately control the pore opening and homogeneity.

\section{Acknowledgements}

The authors are grateful to the Jiangxi Provincial Natural Science Foundation of China (ratification No: 0550050) and the Jiangxi Provincial Department of Education Foundation of China and for the financial support (ratification No: GJJ13731).

\section{References}

1. J.N. Wei, C.L. Gong, Materials Science and Engineering A, 2002, 332, 375-381.

2. C. Gaillard, J.F. Despois, A. Mortensen, Processing of $\mathrm{NaCl}$ powders of controlled size and shape for the microstructural of aluminium foams, Materials Science and Engineering, A, 2004, 374(1-2), 250-262.

3. S. B. Pimientoa, M.E.H. Rojasb, M.E. Palomar, Processing and characterization of open-cell aluminum foams obtained through infiltration processes, Procedia Materials Science, 2015, 9, 54 -61 .

4. J.N. Wei, G.P. Xu, L.L. Zhou, X.Y. Zhou, W.J. Xie, Foamed metal materials preparation technology, Advanced Materials Research, 197-198, 2011,518-521.

5. V. Shapovalov, Porous metals, MRS Bulletin, 1994, 4, 24-29.

6. J. Banhart, J. Baumeister and M. Weber, Damping properties of aluminum foams, Materials Science and Engineering A, 1996, 205, 221-228.

7. J.N. Wei, G.M. Li, L.L. Zhou, X.Y. Zhou, J.M. Yu, T.C. Huang, Effects of macroscopic pores on the damping behaviors of metal materials, Applied Mechanics and Materials, 2011, 66-68, 1155-1162. 